\title{
HOW ROMANIAN IT COMPANIES ADOPTED AGILE PRACTICES AND WHICH ARE THE GENERATED BENEFITS
}

\author{
Maria Daniela LICA \\ Bucharest University of Economic Studies, Romania \\ maria.daniela.lica@gmail.com
}

\begin{abstract}
Agile practices have become the norm in the software development industry to defeat the shortcomings of the Waterfall model. It encourages an innovative and iterative way of working that empowers the teams to be more self-organized and work more closely with their customers. As companies around the world are more and more mature in using Agile, studies show that the most common benefits generated by this way of working are: increased efficiency, improved customer collaboration, better predictability, less technical errors and higher team motivation. My comprehensive studies on the agile way of working helped me identify a list of essential practices that teams should use to reach each one of the benefits mentioned before. While Agile is more prevalent in specific places in the world, there are still counties that are not that mature in applying it. The purpose of my paper is to present the level of adoption of the most common agile practices in Romania and their potential benefits. The study focuses on the software development industry, and it is based on the results of a survey with 200 respondents coming from different IT companies.
\end{abstract}

Keywords: agile way of working, agile practices, software development

JEL classification: D80, C90, D02

DOI: $10.24818 / \mathrm{ie} 2020.02 .03$

\section{Introduction}

In the traditional waterfall methodology, teams used to develop products sequentially: analysts created the whole design upfront, and they wrote down the functional and technical specifications. After this first part, developers started to build the product; then, testers were looking for potential errors, and after they finished all these steps, the client could use and validate it. Nevertheless, with technology developing so fast, we do not have the luxury anymore to spend a lot of time and resources on building products that may become archaic by the time somebody uses them.

Agile evolved as a response to all these challenges. Starting with The Manifesto for Agile Software Development [1], the agile method came up as a set of values and principles that highlight the essence of collaboration, adaptability, and customer-centricity. Instead of working in sequences all the time, Agile encourages an iterative and experimental approach. We start by building a minimum viable product, and we let that product evolve based on the feedback that we receive from the customers. This way, we eliminate the waste from our processes and become more flexible when dealing with changing priorities.

Many practices emerged based on agile values and principles. We use some of them to become more customer-centric or to improve our efficiency and predictability, or it may be to improve the quality of our results. Since motivated individuals are the basis of an agile way of working, some practices also focus on that.

My paper describes how the agile way of working affected the software development industry and which is the level of adoption of the most common agile practices in Romania. 
www.conferenceie.ase.ro

\section{Research method}

The foundation of my study is represented by:

- consulting books, case studies, surveys, and scientific articles

- a survey that provided me with valuable insights regarding the current Agile adoption in Romania and its benefits. The survey had 200 respondents working in 11 different software development companies, having different roles: Developer, Scrum Master, Product Owner, Agile consultant, manager, director, and others; respondents ages vary between $28-55$ years;

- I run the survey during 5 months, between March 2019 - July 2019 and it was filled online, via Typeform tool;

- the size and agile maturity of these companies are described in Figures 1 and 2;

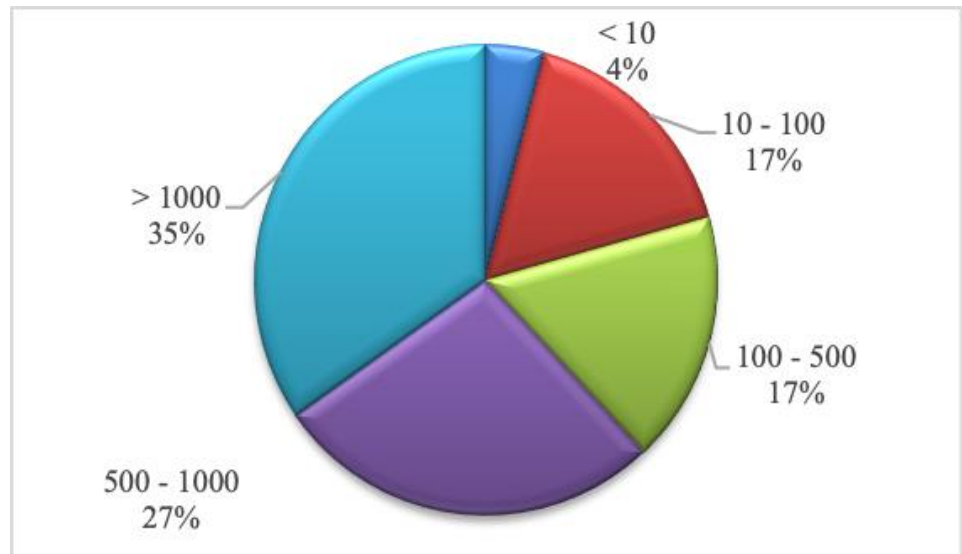

Figure 1. Size of the companies - Number of employees

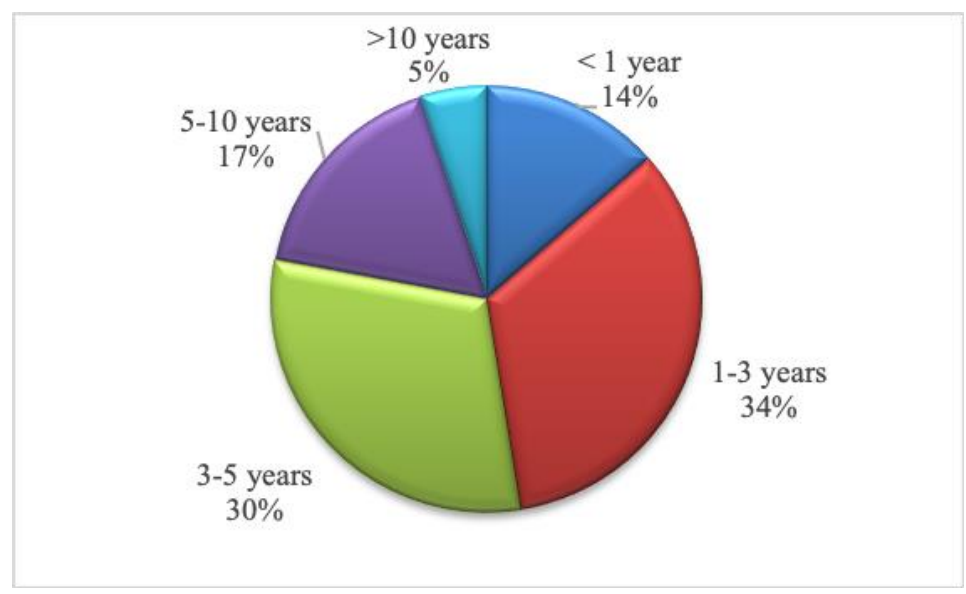

Figure 2. Agile maturity of the companies - Years

- my experience exchange activities with other agile practitioners consolidate my research: events organized by Meetup.com, communities of practice;

- my three and a half years of working experience as an Agile transformation coach in a software development company help me understand the theoretical concepts and how to apply them;

- participating in Agile and Lean training sessions and gaining certifications like Scrum Master, Product Owner, Kanban System Designer, Kanban Management Professional, SAFe Agilist. 
www.conferenceie.ase.ro

\section{Results}

The Agile way of working had a positive impact on most of our respondents. The generated benefits are described below in Figure 3.

The most significant improvements are on the efficiency level since $91 \%$ of the respondents think that it improved or just started to grow lately. Agility had proven its lowest impact on team motivation since only $60 \%$ of the respondents notice improvements in this area.

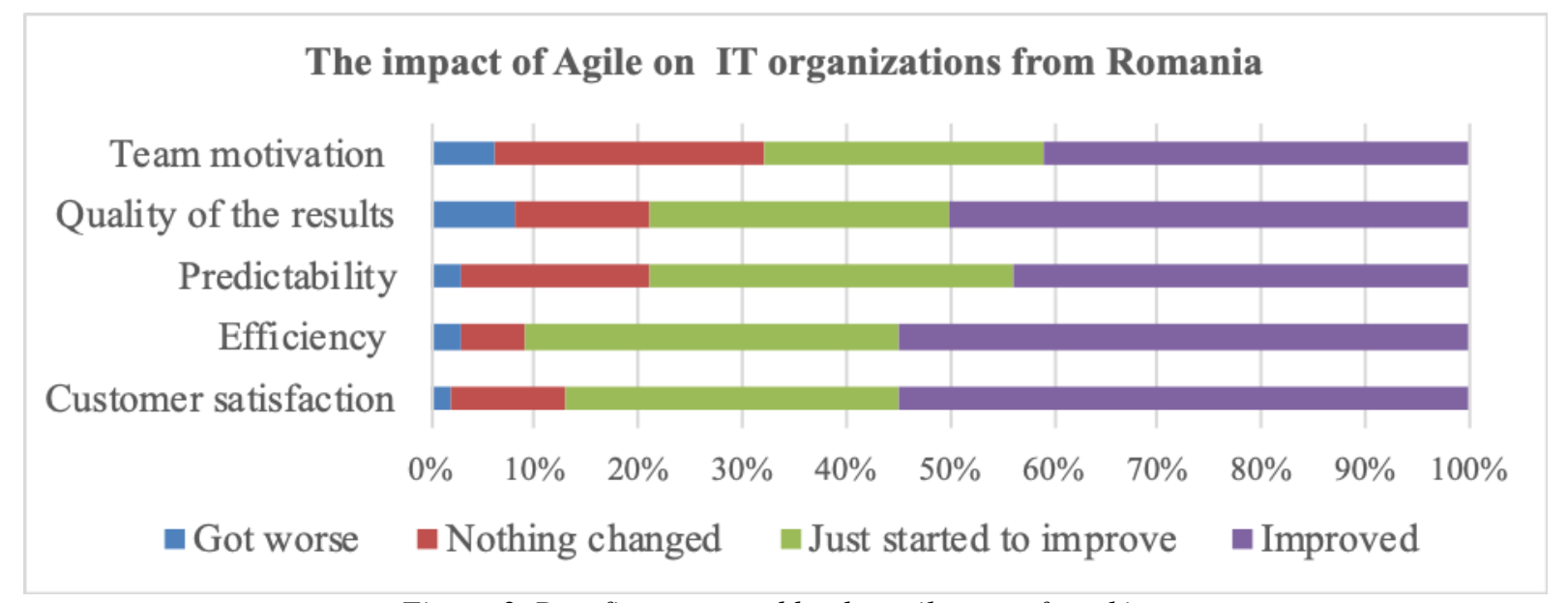

Figure 3. Benefits generated by the agile way of working

My analyses helped me understand which are the most common agile practices that usually lead to these benefits. The second part of the study explores how popular these practices are in Romania.

\section{Usage of practices that influence customer satisfaction}

Team's work is presented to the stakeholders and they provide valuable feedback

The product owner collaborates with the stakeholders to understand their real needs

The product backlog evolves and priorities are adjusted according to the users' needs

The product backlog is continuously refined in a collaborative way

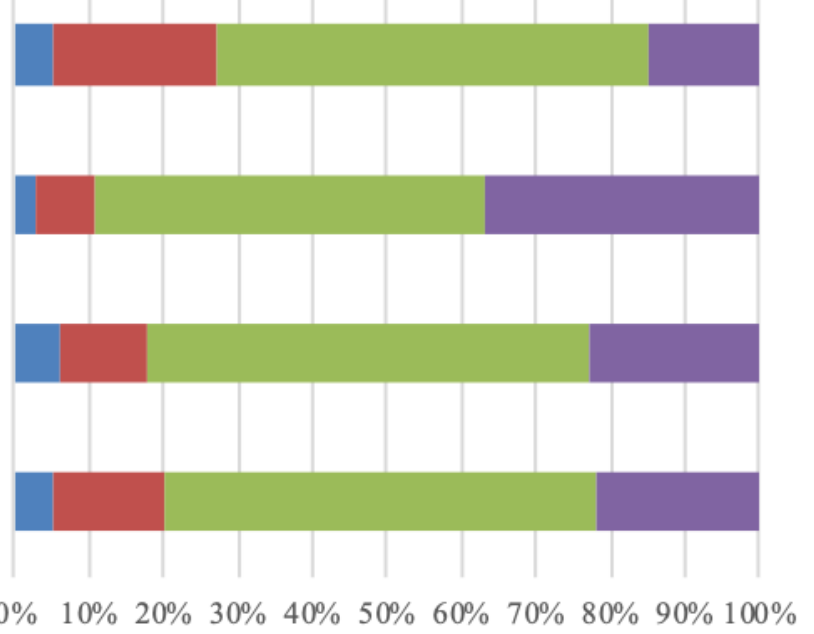

$\square$ Never $\quad$ Few times per year $\quad$ Few times per month $\quad$ Few times per week

Figure 4. Practices that influence customer satisfaction

As we can see in Figure 4, in an agile environment, the Product Owner plays a vital role, since he is the person that collaborates with the stakeholders all the time to understand their needs and adjust the requirements according to their feedback. Almost $90 \%$ of the respondents are 
www.conferenceie.ase.ro

part of agile teams, where the Product Owner discusses with the stakeholders at least a few times per month.

In addition, $80 \%$ of respondents use to adapt their list of tasks at least a few times per month according to the customers changing desires, and a similar number of respondents discuss and refine their requirements in a collaborative way, on the team level.

\section{Usage of practices that influence efficiency}

The Agile facilitator/Scrum Master helps

the team to remove bottlenecks and impediments

The team uses Work in Progress limits (WIP limits) because they want to stop starting and start finishing

Waiting time visible (using columns on the board, for example) because the team wants to be aware of their flow efficiency

Bottlenecks from the system are visible

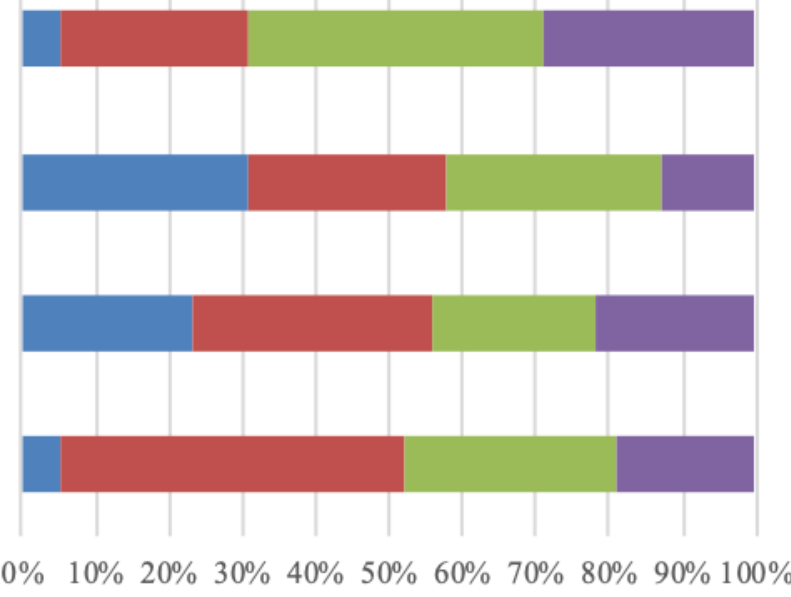

never $\quad$ Sometimes $\quad$ Almost all the time $\quad$ All the time

Figure 5. Practices that influence efficiency

While the product owner role is crucial to increase the customers' satisfaction, the Scrum Master/Agile facilitator role concentrates on improving team efficiency. We can see, in Figure 5 , that more than $90 \%$ of respondents think that the Scrum Master is the impediment remover, which helps the team to deal with bottlenecks and facilitate a smooth flow of work.

On the other hand, practices like work in progress limits, and waiting time transparency are not that used. Being specific to Kanban methodology, these practices are great for improving the efficiency of the flow, but it seems that they are not that common for the Romanian companies.

\section{Usage of practices that may influence predictability}

The team plans the work based on data (ex: velocity, team estimation, capacity)

The product backlog items are small and vertically sliced (they generate business value)

The team uses a burn-down chart to analyse the progress of their work

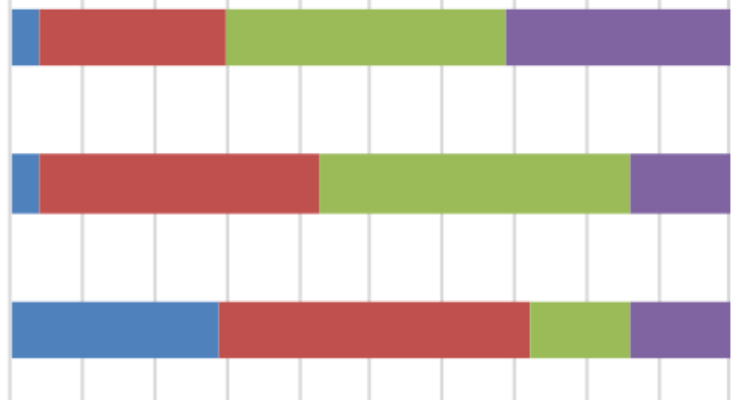

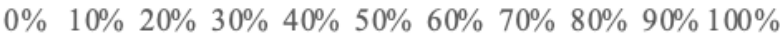

- Never Sometimes Almost all the time All the time 
www.conferenceie.ase.ro

Figure 6. Practices that influence predictability

The predictability of the results is a crucial aspect in an agile environment, especially when using the most common agile methodology - Scrum.

As described in Figure 6, agile teams empirically plan their work, considering their previous velocity. In addition, they try to slice the tasks in smaller pieces that generate value for the customers, enabling fast feedback loops.

\section{Usage of practices that may influence the quality of the results}

\section{The team builds and maintains a} Continuous Delivery Pipeline

The team avoids creating technical debt

Automated acceptance tests are an important part of the definition of done

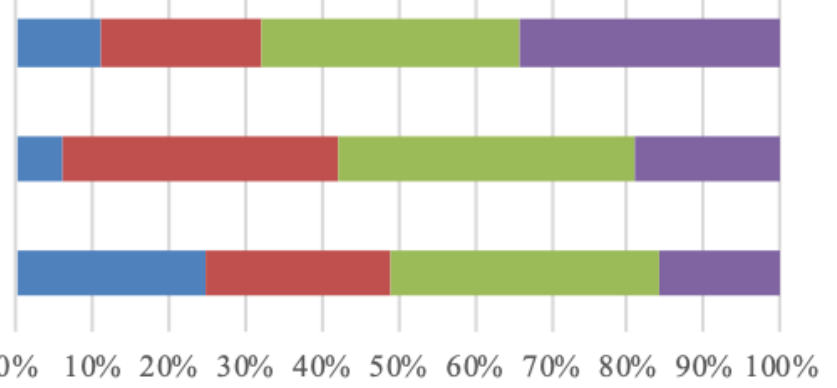

never $\square$ Sometimes $\quad$ Almost all the time $\quad$ All the time

Figure 7. Practices that influence the quality of results

Since the agile teams deliver faster, in an incremental way, they also discover problems faster. To avoid the accumulation of technical errors, they try to fix them immediately and sustainably build the product in the long term. In addition, $90 \%$ of the respondents use a Continuous Delivery Pipeline as an excellent practice to deliver faster and reduce the potential errors from their work. Figure 7 presents the level of usage of some agile practices which are meant to improve the quality of the results.

\section{Usage of practices that may influence team motivation}

The team holds inspect $\&$ adapt sessions that enable them to work on incremental improvements

The team understands the product vision, goals and positive impact that they generate with their actions

The team has the power to self-organise and to take decisions

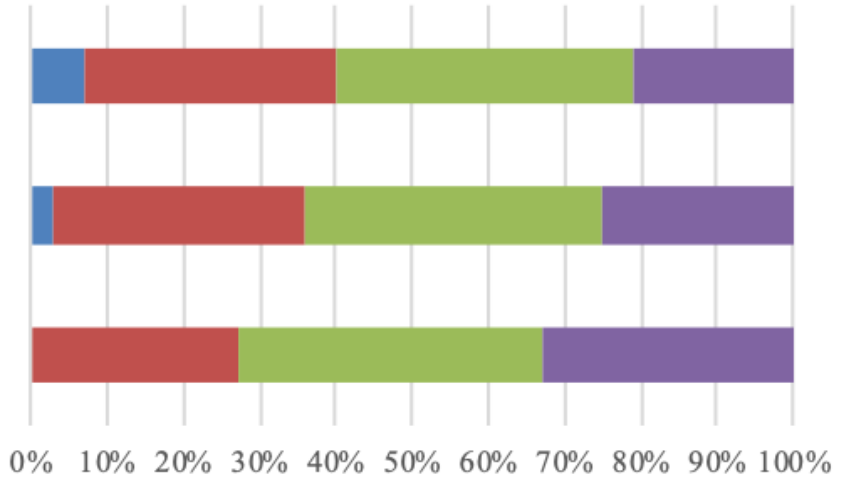

never $\quad$ Sometimes $\quad$ Almost all the time $\quad$ All the time

Figure 8. Practices that influence team motivation

From my point of view, the practices displayed in Figure 8 are essential to boost team motivation, and we should consider them all the time. We can see that they are used all the time by only $20-30 \%$ of our respondents. Having a sense of purpose, clear expectations, and 
www.conferenceie.ase.ro

the autonomy to decide how to meet them should be the norm in the agile way of working. All of these practices are highly correlated with our mindset, and, as far as we can see, there is still room for improvement.

\section{Conclusions}

Analyzing the results of my survey, I can say that the Romanian IT companies also use most of the standard Agile practices. The most significant benefit generated by agile adoption seems to be the increased efficiency of the team. For that, the most common practice used by Romanian teams is to have a specific role - Scrum Master - to help them eliminate the bottlenecks from the system. Agility also had a significant positive impact on customer satisfaction. For that, teams have a specific role - Product Owner - that collaborates with the stakeholders a few times per month or more to understand their needs. The predictability of the teams improved also, and teams managed to do that mostly by making decisions based on historical data, rather than theoretical assumptions. In a more technical direction, we also notice an improvement in the quality of the work. For that, the most common agile practice is to implement a Continuous Delivery Pipeline. Agility had the lowest impact on team motivation. We can see that there is still room for improvement regarding the adoption of the standard agile practices used to influence that: self-organization, a sense of purpose, and recurrent inspect \& adapt sessions.

While introducing some specific agile roles in the way of working seems to generate significant benefits for the agile teams, there are still some sections that need to be improved. These sections are more related to the agile mindset than to the agile process and require more time to be perfected.

\section{References}

[1] The manifesto for Agile Software development, 2001. [Online]. Available: https://agilemanifesto.org/

[2] Version One, "The 13th Annual State of Agile Survey," 2019. [Online]. Available: www.stateofagile.com.

[3] S. M. Graffius, Agile Transformation: A brief Story of How an Entertainment Company Developed New Capabilities and Unlocked Business Agility to Thrive in an Era of Rapid Change, 2019, ISBN-13: 9781072447962

[4] R. C. Martin, Clean Agile: Back to Basics, 2019, United States, ISBN13: 9780135781869

[5] Blokdyk, G., Agile Change Management A Complete Guide, 5starcooks, 2019, ISBN13: 9780655816317

[6] D. K. Rigby, J. Sutherland, A. Noble, Agile at Scale, Insights you need from Harvard Business Review - Agile, Harvard School Publishing Corporation, 2020, ISBN: 978-163369-895-6

[7] L. McGregor, N. Doshi, Why Agile Goes Awry, Insights you needs from Harvard Business Review - Agile, Harvard School Publishing Corporation, 2020, ISBN: 978-1-63369-895-6 